\title{
Tradução de teste de capacidade de memória de trabalho do inglês para o português brasileiro
}

\author{
Translating a working memory capacity test from English to Brazilian Portuguese
}

Pietra Cassol Rigatti ${ }^{1}$, Ana Beatriz Arêas da Luz Fontes ${ }^{2}$, Kelvin Pereira Magagnin ${ }^{3}$, Ingrid Finger ${ }^{4}$

Licenciada em Letras com ênfase em língua portuguesa e inglesa pela Universidade Federa em Psicolinguística pela mesma universidande pesquisa bilinguismo experiência leitora qualidade de representações lexicais e capacidade de memória de trabalho.

E-mail: pietracr@gmail.com

Doutora em Psicologia Cognitiva pela University of Texas at EI Paso, e atualmente Professor da Universidade Federal do Rio Grande do Sul. A professora desenvolve sua pesquisa sobre o processamento de linguagem por indivíduos bilíngues na linha de pesquisa da psicolinguística do Programa de Pos-Graduação em Letras da UFRGS. E-mail: ana.fontes@ufrgs.br

per língua inglesa Tem experiência em pesquisa em Psicolingústica com foco em estudos sobre capacidade de memória de trabalho. Atualmente é professor de língua inglesa no setor privado.

Doutora em Linguistica Aplicada pela PUCRS. É Moderns da Universidade Federan do Rio Grands do Sul, com vínculo permanente ao Programa de Pós-Graduação em Letras. Seus interesses de pesquisa envolvem questões psicolinguísticas e cognitivas relacionadas à aquisição de L2/LE e ao bilinguismo em crianças, adultos e idosos.
RESUMO: O objetivo deste estudo foi a tradução e a adaptação para o contexto brasileiro de um teste de capacidade de Memória de Trabalho (MT) (WATERS e CAPLAN, 1996a). Nossa motivação é a existência de apenas uma medida de MT em português, cujo funcionamento difere do teste em questão. A tradução foi realizada seguindo critérios rígidos de escolha de palavras, número de sílabas, frequência de uso e número de palavras por frase, buscando manter o sentido original das frases. As diferenças entre a medida de MT disponível e a traduzida e suas respectivas vantagens e desvantagens foram explicitadas. Ainda cabem estudos para a validação do teste de capacidade de MT traduzido.

Palavras-chave: Memória de trabalho; Reading span test.

ABSTRACT: The objective of this study was to translate a Working Memory (WM) capacity test (WATERS and CAPLAN, 1996a) into Portuguese, and adapt it to the Brazilian context. Our motivation lies in the fact that there is only one measure of WM available in Portuguese, which works differently from the translated test. The translation followed strict criteria in terms of word choice, number of syllables, frequency of use, and number of words per sentence, while trying to preserve the original meaning of the sentence. The differences between the WM measure available and our translation, as well as the advantages and disadvantages of each are explained. Studies for the validation of the WM capacity test are still necessary.

Keywords: Working memory; Reading span test. 


\section{Introdução}

importância do estudo da Memória de Trabalho (MT) se justifica pelo seu Aenvolvimento em várias atividades cognitivas cotidianas, como "ler uma notícia de jornal, calcular a quantidade certa para a gorjeta no restaurante, mentalmente reorganizar os móveis da sala para acrescentar um novo sofá e comparar várias características de diferentes apartamentos para decidir qual deles alugar" (MIYAKE e SHAH, 1999, p. 1). É importante ressaltar ainda a influência que a MT tem sobre a compreensão textual. Just e Carpenter (1992) explicam que a compreensão da língua é intrinsecamente dependente da habilidade de inter-relacionar informações, as quais podem estar organizadas em diferentes unidades, como frases e orações. Devido a essas inter-relações entre unidades, a leitura demanda que informações sejam mantidas ativas na mente para serem retomadas e utilizadas posteriormente. Todas as tarefas cognitivas citadas requerem vários estágios, cada um com um resultado parcial que precisa ser mantido temporariamente em mente para que a tarefa possa ser realizada com sucesso (MIYAKE e SHAH, 1999). Muitos estudos mostram que essa é a função da MT, isto é, manter algumas informações ativas na mente enquanto outras são processadas (BADDELEY, 2000, 2009; ENGLE, 2002, 2010; JUST e CARPENTER, 1992; MIYAKE e SHAH, 1999; RICKER, AUBUCHON e COWAN, 2010; WATERS, CAPLAN e HILDEBRANDT, 1987).

Essa função da MT tem um impacto direto em muitos aspectos cognitivos, incluindo domínios linguísticos e não linguísticos. No que tange os domínios linguísticos, a MT auxilia na resolução de ambiguidade sintática (HAVIK et al., 2009) e lexical (ARÊAS DA LUZ FONTES e SCHWARTZ, 2011), no processamento semântico (ARDILA, 2003), na performance em leitura (SILVEIRA, 2011) e escrita em L2 (SÁEZ, 2004) e na compreensão e produção de L2; (LINCK et al., 2014). Além disso, a MT é importante no estudo de indivíduos no espectro autista (MACIZO, SORIANO e PAREDES, 2016), no estudo da afasia (IVANOVA e
HALLOWELL, 2014), da esquizofrenia (HASHIMOTO et al., 2010), da percepção do discurso em participantes ouvintes e com implantes cocleares (MOBERLY et al., 2017), do controle de atenção no envelhecimento (MILLMAN e MATTYS, 2017) e do esquecimento (WEISBERG e NEWCOMBE, 2016).

Devido a tal importância, é necessário que a MT seja estudada de forma mais rígida e controlada, tanto com relação a aspectos psicológicos quanto linguísticos. Assim, o objetivo deste estudo é a tradução e a adaptação para o contexto brasileiro de um teste de Capacidade de Memória de Trabalho, mais especificamente, o reading span test de Daneman e Carpenter (1980) adaptado por Waters, Caplan e Hildebrandt (1987) e Waters e Caplan (1996a). Esse teste já foi utilizado em diversos estudos e atendeu às expectativas (WALTER, 2007; YEH, 2011; CÁCERES, 2012). Além disso, temos acesso a apenas uma medida de MT em português no momento, a Bateria de Avaliação de Memória de Trabalho (BAMT-UFMG) (WOOD et al., 2001), cujo funcionamento difere do reading span de Waters e Caplan (1996a).

\section{Memória de Trabalho: construto e sua medição}

O termo Memória de Trabalho (MT) foi utilizado primeiramente por Miller, Galanter e Pribram em 1960 (apud BADDELEY, 2000) para se referirem a uma função atribuída à Memória de Curto Prazo (MCP). Anteriormente a isso, os estudos se referiam apenas à MCP e à Memória de Longo Prazo (MLP), que seriam responsáveis respectivamente pelo armazenamento de informações temporariamente e permanentemente. Ainda hoje, porém, não há uma distinção clara entre os conceitos de MT e de MCP (BADDELEY, 2000, 2009; MIYAKE e SHAH, 1999). De acordo com Baddeley e Hitch (1974, apud BADDELEY, 2009), o termo 'memória de trabalho' enfatiza a função desse sistema em atividades cognitivas, trabalho mental e raciocínio lógico, enquanto os modelos de MCP anteriores tinham como foco primário 
o armazenamento de informações. A MT é considerada um sistema cognitivo responsável pelo processamento e armazenamento, por um curto período de tempo, de informações a serem utilizadas em tarefas cognitivas complexas, como o raciocínio, a resolução de problemas e a compreensão leitora (BADDELEY, 2000, 2009; ENGLE, 2002, 2010; JUST e CARPENTER, 1992; MIYAKE e SHAH, 1999; RICKER et al., 2010; WATERS et al., 1987). De acordo com Baddeley (1992), o estudo da MT pode ser dividido em dois tipos: estudos que visam observar e explicar as estruturas da memória de trabalho (BADDELEY, 1990), e os que têm por objetivo investigar diferenças individuais de capacidade de MT e suas possíveis (cor)relações com outros construtos cognitivos (DANEMAN e CARPENTER, 1980; ENGLE, KANE e TUHOLSKI, 1999). Em relação aos estudos de diferenças individuais, Daneman e Carpenter (1980) sugerem que a capacidade de memória de trabalho é específica para cada indivíduo e varia de acordo com a demanda da tarefa. Para a medição dessa eficiência é necessário uma medida de processamento e armazenamento de informações por um curto período de tempo na MT.

Uma das maneiras mais comuns de se avaliar a MT é através da medição de sua capacidade, mais especificamente, do limite da capacidade de processamento da MT. Para Just e Carpenter (1992), capacidade/limite é a quantidade máxima de ativação de um elemento - que pode ser uma palavra, frase, proposição, estrutura sintática, entre outros - disponível na MT para sustentar ambas as suas funções de processamento e armazenamento. Essa capacidade já foi medida através de uma gama de testes de capacidade de MT, como digit ou wordspan, reading ou operationspan, antisaccade e dichoticlistening tests. Testes de span podem ser simples ou complexos. Os simple spantests mais comuns são o digit span e o word span. Eles são compostos de uma lista de elementos, dígitos ou palavras, a serem lembrados em ordem, posteriormente à apresentação individual dos elementos. De acordo com
Engle (2010), simple span tests eram utilizados principalmente para medição de MCP. Se for acrescentada a um digit ou word span test a tarefa de leitura e de julgamento de uma frase ou a tarefa de resolver uma operação matemática, teremos um complex span test. Dois exemplos são o reading e o operation span tests, que consistem na realização de duas tarefas concomitantemente: a leitura e o julgamento do sentido de uma frase, ou a resolução de uma operação matemática e a memorização de elementos, como dígitos, letras ou palavras. Os complex span tests demandam tanto armazenamento, que consiste na manutenção de elementos na mente, quanto processamento cognitivo dos estímulos, que está presente no julgamento semântico das frases ou na resolução de operações matemáticas. Além disso, cada um desses testes procura medir uma habilidade diferente: o operation span, por exemplo, avalia habilidades numéricas; o listening span, habilidades de escuta; o speaking span, habilidades de produção oral; o symmetry span, habilidades de percepção espacial; e o reading span, habilidades de leitura (PREBIANCA, 2013; OSWALD et al., 2015).

$\mathrm{O}$ primeiro reading span test, que era composto por séries de frases independentes umas das outras, de comprimento entre 13 e 16 palavras, e que deveriam ser lidas em voz alta, foi desenvolvido por Daneman e Carpenter (1980). A palavra final de cada frase deveria ser memorizada e relembrada posteriormente. Esse teste foi muito influente em estudos seguintes e foi utilizado por Waters et al. (1987), Just e Carpenter (1992), Waters e Caplan (1996a) e Walter (2007). Uma versão dele em português foi utilizada por Tomitch $(1995,1999-2000)$ e Bailer (2011). Além disso, outras modificações foram realizadas, como o encurtamento de frases para a avaliação de indivíduos afásicos (CASPARI et al., 1998), a adaptação para um listening span test em inglês (SWANSON e SACHSE-LEE, 2001) e um em italiano (BELACCHI, BENELLI e PANTALEONE, 2011), a modificação da tarefa de leitura para conter uma decisão inferencial (CARRIEDO, ELOSÚA 
e GARCÍA-MADRUGA, 2011) e o encurtamento de frases em uma versão em sueco (SÖRQVIST e RÖNNBERG, 2012). Essas versões também se propõem a medir capacidade de MT, assim como o teste original de Daneman e Carpenter (1980).

Contudo, Waters e Caplan (1996a) argumentam que o teste de Daneman e Carpenter (1980) de fato requer tanto processamento quanto armazenamento para ser realizado, porém ele serve de medição apenas para armazenamento. Waters e Caplan (1996a) sugerem que a leitura em voz alta não se encaixa como um teste de medição de processamento. Esse argumento fundamenta a modificação feita por Waters et al. (1987) e Waters e Caplan (1996a) no teste original de Daneman e Carpenter (1980). Ao invés de apenas ler as frases em voz alta, o participante deveria também julgar a sua aceitabilidade semântica - em outras palavras, se a frase faz sentido, é coerente - além de memorizar as palavras finais. Assim, o teste passaria a medir armazenamento e também processamento. Ainda, as frases selecionadas para o teste deveriam pertencer a uma das seguintes estruturas sintáticas: clivada de sujeito, clivada de objeto, relativa de sujeito e relativa de objeto. Alguns exemplos dessas estruturas são, respectivamente,

(1) Foi o empregado que quis o aumento.

(2) Foi o assalto que o policial evitou.

(3) 0 carro em que o presidente andou foi feito para uma atriz.

(4) O garçom serviu o café que o cliente pediu.

Desse modo, os pesquisadores poderiam também verificar a influência da complexidade sintática no processamento cognitivo. Essa complexidade pode ser ampliada se a leitura em voz alta das frases for utilizada, como realizado por Tomitch $(1995,1999-2000)$ e Bailer (2011), com o teste de Daneman e Carpenter (1980) em português.
Atualmente no Brasil existe apenas um teste de capacidade de MT validado disponível em português. Na verdade, se trata de uma bateria de testes, que apresenta um funcionamento diferente do teste de Waters e Caplan (1996a). A Bateria de Avaliação de Memória de Trabalho (WOOD et al., 2001) contém três subtestes verbais e três subtestes numéricos, que são versões de reading span, operation span, digit span e word span tests. A BAMT se propõe a medir três componentes funcionais que, de acordo com Salthouse e Babcock (1991), são característicos da Memória de Trabalho: capacidade de coordenação, capacidade de armazenagem e eficiência de processamento (velocidade) (WOOD et al., 2001). O subteste verbal relacionado à capacidade de coordenação é similar ao reading span test adaptado por Waters et al. (1987), porém as frases são ouvidas e não lidas. O participante responde em um caderno a uma pergunta objetiva de compreensão textual e, ao final de um bloco de perguntas, escreve a palavra final de cada uma delas. Esse subteste pretende medir a capacidade de coordenação entre compreensão de frases e retenção de palavras. 0 subteste verbal relacionado à capacidade de armazenagem apresenta ao participante uma lista de palavras a serem memorizadas e escritas em ordem de apresentação. Esse teste procura medir processamento (manutenção da ordem das palavras apreendidas) e, principalmente, armazenamento. No subteste relacionado à eficiência de processamento, o participante deve ler e responder a 25 perguntas curtas, com três alternativas cada, o mais rápido possível. Esse subteste é responsável por avaliar o armazenamento e a velocidade de processamento de informações. Além dos subtestes verbais já descritos, há subtestes numéricos similares para cada componente funcional, que ao invés de palavras e frases utilizam dígitos e operações respectivamente.

No caso da BAMT, é o conjunto dos seis subtestes que indica a capacidade de MT do participante. Duas diferenças entre o reading span test de Waters e Caplan (1996a) e a BAMT são o fato de ser uma bateria de longa duração e 
de difícil aplicação, especialmente por necessitar ser feita em duas sessões, e o fato de ser um teste offline, isto é, não medir o processamento cognitivo no momento da realização do teste, como no caso de um teste de tempo de reação, por exemplo, e sim após a realização do teste.

Testes como os citados acima precisam gerar resultados constantes ao serem aplicadas múltiplas vezes. Para tanto, Engle (2010) enfatiza a importância de serem mantidos padrões no mínimo satisfatórios de confiabilidade e de validade durante a aplicação de testes. Desse modo, os resultados obtidos têm menor probabilidade de serem equivocados. Ele explica que uma medição é válida quando ela de fato prevê o desempenho de um sujeito em determinado teste e é confiável quando é consistente em relação às diferentes aplicações do teste em um mesmo sujeito (ENGLE, 2010).

A BAMT já é um teste validado e confiável (WOOD et al., 2001) e já foi utilizado em outros contextos (AZEVEDO; 2012; CÁCERES, 2012; VIEIRA, 2015). Apesar disso, precisamos de outras opções de testes de capacidade de Memória de Trabalho em português. Por isso, fizemos a tradução para o português e adaptação para o contexto brasileiro do reading span test de Waters e Caplan (1996a) para que no futuro possa ser validado.

\section{Método}

O objetivo deste estudo é a tradução e a adaptação do teste de capacidade de Memória de Trabalho de Waters e Caplan (1996a) para o contexto brasileiro. A seguir, são apresentados os critérios que foram utilizados durante a tradução dos estímulos do teste.

\subsection{Tradução e adaptação do teste de MT}

$\mathrm{O}$ teste de MT original utilizado no presente estudo (WATERS, CAPLAN e HILDEBRANDT, 1987; WATERS e CAPLAN, 1996a) é um reading span test e foi criado para auxiliar a determinar o papel da MT e de seus subsistemas (BADDELEY e HITCH, 1974) na compreensão de frases escritas. O participante deve realizar duas tarefas ao mesmo tempo: julgar a aceitabilidade semântica de frases de quatro organizações sintáticas diferentes enquanto retém na mente a última palavra de cada frase. Waters, Caplan e Hildebrandt (1987) utilizaram 200 frases aceitáveis e 200 não aceitáveis, divididas igualmente em quatro conjuntos de acordo com sua categoria sintática: clivada de sujeito, clivada de objeto, relativa de sujeito, relativa de objeto. A aceitabilidade semântica das frases dependia da animacidade do sujeito e do objeto das frases. Por exemplo, a frase aceitável em (5) pode dar origem à frase não aceitável em (6).

(5) Foi o homem que agarrou a almofada.

(6) Foi a almofada que agarrou o homem.

Os participantes deveriam ler silenciosamente a frase em uma tela de computador e apertar um botão caso fosse aceitável e outro caso não fosse. Feito o julgamento, uma nova frase apareceria automaticamente na tela. Ao final de um bloco de frases, que variavam de 2 a 6 frases por bloco, os participantes deveriam relembrar as palavras finais de cada frase na ordem de aparecimento.

Os estímulos do reading span test, anteriormente utilizados e gentilmente cedidos por Yeh (2011), foram traduzidos e adaptados para o contexto brasileiro conforme os seguintes critérios. As palavras finais foram controladas de modo que nunca se repetissem durante o teste, do contrário haveria maior facilidade de execução do teste, e para que nunca tivessem comprimento maior do que três sílabas, evitando assim dificuldade excessiva na memorização. Ainda com relação ao controle das palavras finais, procuramos impedir que os últimos fonemas das palavras finais se 
repetissem dentro de um mesmo bloco para que não ocorresse facilitação da memorização dessas palavras. Restringimos as palavras finais às categorias de substantivo, adjetivo ou verbo apenas, excluindo da posição final das frases advérbios, para evitar palavras com mais de três sílabas, e preposições, por não serem comuns nessa posição no português. Também evitamos expressões específicas do estado do Rio Grande do Sul, como a palavra "tri" que pode ser usada como adjetivo e advérbio, para que o teste possa ser utilizado em todo o país. Esses critérios foram definidos subjetivamente por três dos autores do estudo, que são nativos e residentes do estado do Rio Grande do Sul.

Tivemos acesso a uma versão em espanhol ${ }^{1}$ das frases do teste e as analisamos para auxiliar na nossa tradução. Em muitos momentos, percebemos que o sentido das frases em inglês não havia sido mantido nas frases em espanhol. Por isso, procuramos manter o significado original o mais intacto possível, sempre preservando a estrutura sintática. Entretanto, em frases como em (7), tivemos dificuldades em manter o sentido original de modo natural para o falante brasileiro. Portanto, optamos por modificar a frase mais drasticamente e obtivemos o exemplo em (8).

(7) It was the actor that the Academy Award won.

(8) Foi o fusca que o poste da rua derrubou.

Pudemos preservar não apenas a estrutura sintática, mas também a aceitabilidade da frase, o número de palavras e de sílabas. Além disso, seu conteúdo semântico se tornou mais familiar para o falante brasileiro, devido a critérios de tradução que consideraram tanto fatores linguísticos quanto culturais.

${ }^{1}$ Correspondência pessoal de uma das autoras.
No mesmo sentido, modificamos algumas palavras durante a tradução para que fizessem mais sentido para o público brasileiro. Por exemplo, trocamos "chili" por "feijoada" já que a última é muito mais comumente utilizada no país do que a primeira. Além disso, uma de nossas principais preocupações foi manter similar o número de palavras e de sílabas nas frases para que a versão em português do teste fosse o mais parecida possível à original de Waters e Caplan (1996a). Em função das diferenças entre os sistemas silábicos do inglês e do português, ao invés do número de sílabas presentes nas frases, controlamos o número de palavras na frase e o seu comprimento. Além disso, demos atenção especial às palavras finais, que deveriam ser relembradas pelos participantes. Em uma breve aplicação do teste com poucos participantes, percebemos que palavras finais com mais de três sílabas poderiam tornar o teste muito exigente. Por essa razão, limitamos o tamanho das palavras finais a no máximo três sílabas. Esses critérios podem ser verificados nos Quadros 1 a 4 inseridos na seção 3.

\section{Resultados}

Os Quadros 1 a 4 apresentam as frases do teste original separadas por estrutura sintática e por aceitabilidade semântica na coluna da esquerda. Neles também estão incluídas, na coluna do meio, as frases traduzidas para a versão em espanhol do mesmo teste, que utilizamos como auxílio para a nossa tradução. Na coluna à direita, estão as frases finais já traduzidas e adaptadas para o contexto brasileiro. Por fim, é importante salientar que a ordem de apresentação das frases na tarefa foi aleatória, alternando as condições dentro de cada bloco, e não como aparece na discussão dos resultados a seguir 
Quadro 1 - Processo de tradução das frases clivadas de sujeito.

\begin{tabular}{|c|c|c|c|c|c|c|c|c|c|}
\hline & № & Original & Espanhol & Tradução & & № & Original & Espanhol & Tradução \\
\hline \multirow{22}{*}{ 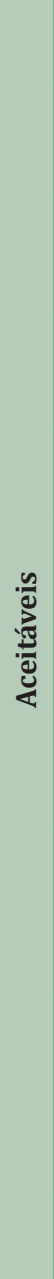 } & 1 & $\begin{array}{l}\text { It was the employee that } \\
\text { wanted the raise. }\end{array}$ & $\begin{array}{l}\text { Era la niña que amaba el } \\
\text { perro. }\end{array}$ & $\begin{array}{l}\text { Foi o empregado que quis o } \\
\text { bônus. }\end{array}$ & \multirow{22}{*}{ 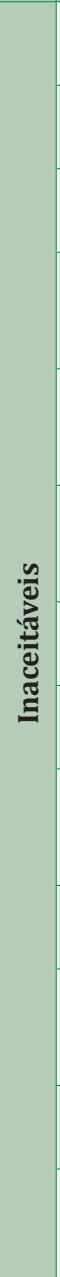 } & 14 & $\begin{array}{l}\text { It was the purse that } \\
\text { snatched the thief. }\end{array}$ & $\begin{array}{l}\text { La bolsa es la que le robo a la } \\
\text { señora. }\end{array}$ & $\begin{array}{l}\text { Foi a bolsa quem roubou o } \\
\text { ladrão. }\end{array}$ \\
\hline & \multirow[t]{2}{*}{2} & \multirow{2}{*}{$\begin{array}{l}\text { It was the party that Julia } \\
\text { hosted that woke the } \\
\text { neighbors. }\end{array}$} & \multirow{2}{*}{$\begin{array}{l}\text { Fue el cálculo que el científico } \\
\text { explicó lo que impactó a la } \\
\text { audiencia. }\end{array}$} & \multirow{2}{*}{$\begin{array}{l}\text { Foi a festa que Julia deu que } \\
\text { acordou os vizinhos. }\end{array}$} & & 15 & $\begin{array}{l}\text { It was the cookie who ate } \\
\text { the youngest child. }\end{array}$ & $\begin{array}{l}\text { El pastel fue lo que se comió } \\
\text { al joven. }\end{array}$ & $\begin{array}{l}\text { Foi o biscoito quem comeu a } \\
\text { menina. }\end{array}$ \\
\hline & & & & & & 16 & $\begin{array}{l}\text { It was the heartburn that } \\
\text { gave the man chili. }\end{array}$ & $\begin{array}{l}\text { Fue la ternura que dió al } \\
\text { enamorado canción. }\end{array}$ & $\begin{array}{l}\text { Foi a azia que deu feijoada } \\
\text { no senhor. }\end{array}$ \\
\hline & 3 & $\begin{array}{l}\text { It was the boy with the } \\
\text { sprained thumb that sat on } \\
\text { the big chair. }\end{array}$ & $\begin{array}{l}\text { Fue el ladrón con pistola que } \\
\text { asesinó en la parte trasera. }\end{array}$ & $\begin{array}{l}\text { Foi o menino com o dedo } \\
\text { machucado que sentou na } \\
\text { cadeira grande. }\end{array}$ & & \multirow[b]{2}{*}{17} & \multirow{2}{*}{$\begin{array}{l}\text { It was the teacher that had } \\
\text { to be graded by the last set } \\
\text { of papers. }\end{array}$} & \multirow{2}{*}{$\begin{array}{l}\text { Los resultados son los que } \\
\text { tienen que recoger a la } \\
\text { enfermera. }\end{array}$} & \multirow{2}{*}{$\begin{array}{l}\text { Foi o professor que teve de } \\
\text { ser corrigido pelos trabalhos } \\
\text { finais. }\end{array}$} \\
\hline & \multirow{3}{*}{4} & \multirow{3}{*}{$\begin{array}{l}\text { It was the player in the red } \\
\text { shorts who broke his arm. }\end{array}$} & \multirow{3}{*}{$\begin{array}{l}\text { Fue el joven de mirada } \\
\text { profunda quien recitó su } \\
\text { poema. }\end{array}$} & \multirow{3}{*}{$\begin{array}{l}\text { Foi o jogador de calção } \\
\text { vermelho que quebrou o } \\
\text { braço. }\end{array}$} & & & & & \\
\hline & & & & & & \multirow{3}{*}{18} & \multirow{3}{*}{$\begin{array}{l}\text { It was the talent contest that } \\
\text { entered the dancers. }\end{array}$} & \multirow{3}{*}{$\begin{array}{l}\text { Es el conquistador en lo que } \\
\text { se escribió la jornada. }\end{array}$} & \multirow{3}{*}{$\begin{array}{l}\text { Foram os concursos } \\
\text { talentosos que participaram } \\
\text { dos artistas. }\end{array}$} \\
\hline & & & & & & & & & \\
\hline & \multirow{2}{*}{5} & \multirow{2}{*}{$\begin{array}{l}\text { It was the plumber that } \\
\text { unclogged the drain. }\end{array}$} & \multirow{2}{*}{$\begin{array}{l}\text { El carpintero fue él que } \\
\text { compuso la silla. }\end{array}$} & \multirow{2}{*}{$\begin{array}{l}\text { Foi o encanador que } \\
\text { desentupiu a pia. }\end{array}$} & & & & & \\
\hline & & & & & & & It was the document & & \\
\hline & \multirow[t]{2}{*}{6} & \multirow{2}{*}{$\begin{array}{l}\text { It was the newspaper article } \\
\text { that angered the murder } \\
\text { suspect. }\end{array}$} & $\begin{array}{l}\text { Fue la gran canción que hizo } \\
\text { bailar a todos los asistentes. }\end{array}$ & $\begin{array}{l}\text { Foi o artigo do jornal que } \\
\text { irritou o suspeito do crime. }\end{array}$ & & 19 & $\begin{array}{l}\text { that shredded the angry } \\
\text { cats. }\end{array}$ & $\begin{array}{l}\text { Es el perro lo que la comida } \\
\text { vomitó. }\end{array}$ & $\begin{array}{l}\text { Foram os documentos que } \\
\text { rasgaram os gatos. }\end{array}$ \\
\hline & & & & & & 20 & It was the Gatorade that & Fue la medicina quien tomo & Foi o Gatorade quem bebeu \\
\hline & 7 & It was the doctor that wrote & Fue el atleta quien corrio muy & Foi o médico que receitou o & & & drank the athletes. & la enferma. & \\
\hline & & It was the tornado reported & & & & 21 & $\begin{array}{l}\text { It was the egg that laid the } \\
\text { chicken. }\end{array}$ & $\begin{array}{l}\text { Fue la fiesta que use en el } \\
\text { sombrero. }\end{array}$ & $\begin{array}{l}\text { Foi o ovo que botou a } \\
\text { galinha. }\end{array}$ \\
\hline & 8 & $\begin{array}{l}\text { on the news that destroyed } \\
\text { the village. }\end{array}$ & $\begin{array}{l}\text { poca cosecha. } \\
\text { provoco }\end{array}$ & jornais que destruiu a vila. & & & It was the sleeping & Fue la gran canción que & Foi o casal dormindo que \\
\hline & 9 & It was the fisherman that & Fue la niña quien dibujo la & Foi o pescador quem pegou & & 22 & loud noise. & & \\
\hline & & caught the trout. & & & & & It was the hallway that & Fue la pista quien corrio muy & Foi o salão quem varreu o \\
\hline & 10 & It was the neighbor that & Fue el pasajero que visitó la & Foi o vizinho que destruiu & & 23 & swept the janitor. & & zelador. \\
\hline & & & & & & & It was the child with a & & Foi o rapaz com um selo \\
\hline & 11 & $\begin{array}{l}\text { It was the computer with } \\
\text { the broken hard drive that }\end{array}$ & $\begin{array}{l}\text { Era la bolsa con rayas azules } \\
\text { que estaba en la cama. }\end{array}$ & $\begin{array}{l}\text { Foi a bolsa que Marta } \\
\text { ganhou que estava na cama. }\end{array}$ & & 24 & $\begin{array}{l}\text { foreign stamp that intrigued } \\
\text { the letter. }\end{array}$ & largo que revisó la secretaria. & $\begin{array}{l}\text { estrangeiro que interessou } \\
\text { a carta. }\end{array}$ \\
\hline & & $\begin{array}{l}\text { sat on the table. } \\
\text { It was the secretary that }\end{array}$ & Fue la avispa que picó al & Foi a secretária que anotou & & 25 & $\begin{array}{l}\text { It was the story that told the } \\
\text { librarian. }\end{array}$ & $\begin{array}{l}\text { Era la receta que tenía la } \\
\text { suegra. }\end{array}$ & $\begin{array}{l}\text { Foi a história quem contou } \\
\text { uma vovó. }\end{array}$ \\
\hline & 12 & took the message. & cerdito. & o recado. & & & It was a turnip and not a & & Era uma batata e não uma \\
\hline & 13 & $\begin{array}{l}\text { It was the bodybuilder that } \\
\text { lifted the barbell. }\end{array}$ & $\begin{array}{l}\text { Es el atleta el que corrió diez } \\
\text { millas. }\end{array}$ & $\begin{array}{l}\text { Foi o atleta que levantou o } \\
\text { peso. }\end{array}$ & & 26 & $\begin{array}{l}\text { recipe that was called for in } \\
\text { the carrot. }\end{array}$ & $\begin{array}{l}\text { Era el gato y no la hermana } \\
\text { lo que quería la rata. }\end{array}$ & $\begin{array}{l}\text { receita que fazia parte da } \\
\text { cenoura. }\end{array}$ \\
\hline
\end{tabular}

Fonte: Elaborado pelos autores. 
No Quadro 1, é possível perceber que procuramos manter o sentido das frases clivadas de sujeito traduzidas para o português o mais próximo possível do sentido original. Entretanto, fizemos modificações para evitar que as traduções criassem frases mais longas que as originais ou com palavras finais que contivessem mais que três sílabas. Por exemplo, a frase 6, It was the newspaper article that angered the murder suspect, foi modificada para Foi o artigo do jornal que irritou o suspeito do crime, pois "assassinato" tem cinco sílabas, o que poderia dificultar a memorização das palavras finais. Além disso, a frase 11, It was the computer with the broken hard drive that sat on the table, foi modificada para Foi a bolsa que Marta ganhou que estava na cama, pois, após nossa tradução, o número de sílabas e de palavras da frase era superior ao da frase original. Então, utilizamos como modelo a frase em espanhol e mudamos o sentido da frase original.

Também fizemos modificações quando o contexto demandou ou permitiu para que os significados fossem mais facilmente reconhecidos pelo público brasileiro. Por exemplo, a frase 25, It was the story that told the librarian, foi modificada para Foi a história que contou uma vovó, devido ao fato de que, no Brasil, não é comum o hábito de bibliotecários contarem histórias. Porém, em um contexto mais familiar, as chances seriam maiores de uma vovó fazêlo. Do mesmo modo, a frase 26, It was a turnip and not a recipe that was called for in the carrot, foi traduzida para Era uma batata e não uma receita que fazia parte da cenoura, porque nabos são menos comuns na alimentação brasileira do que batatas.

Esses são apenas alguns exemplos de como nossos critérios foram aplicados durante a tradução das frases clivadas de sujeito. Nos Quadros 2 a 4, ilustraremos outros critérios.

No Quadro 2, é possível observar outro critério de tradução das frases clivadas de objeto. Houve momentos em que realizamos mudança no tempo verbal da palavra final das frases. Por exemplo, a frase 30, It was the chicken that the chef fried, poderia ser traduzida para Foi o frango que o cozinheiro fritou. Contudo, optamos por traduzi-la para Foi o frango que o cozinheiro fritava, de modo a evitar que, naquele bloco de frases, duas palavras finais terminassem em -ou. Caso a última sílaba das palavras finais em um mesmo bloco de frases se repetisse, modificamos essa terminação através de mudança de tempo verbal ou de palavra final. Assim, procuramos evitar que repetições em palavras finais pudessem facilitar a memorização dessas palavras.

Quadro 2 - Processo de tradução das frases clivadas de objeto.

\begin{tabular}{|c|c|c|c|c|}
\hline & № & Original & Espanhol & Tradução \\
\hline \multirow{6}{*}{ 总 } & 27 & $\begin{array}{l}\text { It was the poisonous plant } \\
\text { that the child ate. }\end{array}$ & $\begin{array}{l}\text { Fue la herida profunda que } \\
\text { la espada hizo. }\end{array}$ & $\begin{array}{l}\text { Foi uma planta venenosa } \\
\text { que a criança ingeriu. }\end{array}$ \\
\hline & 28 & $\begin{array}{l}\text { It was the washing machine } \\
\text { that the repairman fixed. }\end{array}$ & $\begin{array}{l}\text { El jarrón es lo que hizo el } \\
\text { indígena. }\end{array}$ & $\begin{array}{l}\text { Foi a máquina de lavar que } \\
\text { o homem consertou. }\end{array}$ \\
\hline & 29 & $\begin{array}{l}\text { It was the robbery that the } \\
\text { police officer prevented. }\end{array}$ & $\begin{array}{l}\text { Fue el beso que el galán de } \\
\text { cine simuló. }\end{array}$ & $\begin{array}{l}\text { Foi o assalto que o policial } \\
\text { evitou. }\end{array}$ \\
\hline & 30 & $\begin{array}{l}\text { It was the chicken that the } \\
\text { chef fried. }\end{array}$ & $\begin{array}{l}\text { Fue la casa que el albañil } \\
\text { construyo. }\end{array}$ & $\begin{array}{l}\text { Foi o frango que o } \\
\text { cozinheiro fritava. }\end{array}$ \\
\hline & 31 & $\begin{array}{l}\text { It was the mansion that the } \\
\text { fire consumed. }\end{array}$ & $\begin{array}{l}\text { Fue el arquitecto quien } \\
\text { diseño el edificio. }\end{array}$ & $\begin{array}{l}\text { Foi a mansão que o fogo } \\
\text { queimou. }\end{array}$ \\
\hline & 32 & $\begin{array}{l}\text { It was the soap opera that } \\
\text { the housekeeper watched. }\end{array}$ & $\begin{array}{l}\text { Era el dulce que la canasta } \\
\text { contenía. }\end{array}$ & $\begin{array}{l}\text { Foi a novela das oito que a } \\
\text { dona de casa assistiu. }\end{array}$ \\
\hline \multirow{6}{*}{ 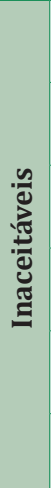 } & 33 & $\begin{array}{l}\text { It was the actor that the } \\
\text { Academy Award won. }\end{array}$ & $\begin{array}{l}\text { Fue el sombrero que el mago } \\
\text { usó. }\end{array}$ & $\begin{array}{l}\text { Foi o fusca que o poste da } \\
\text { rua derrubou. }\end{array}$ \\
\hline & 34 & $\begin{array}{l}\text { It was the boy that the } \\
\text { thunder heard. }\end{array}$ & $\begin{array}{l}\text { Fue la radio que escucho en } \\
\text { la canción. }\end{array}$ & $\begin{array}{l}\text { Foi o menino que o trovão } \\
\text { ouviu. }\end{array}$ \\
\hline & 35 & $\begin{array}{l}\text { It was the student by } \\
\text { Chomsky that the book read. }\end{array}$ & $\begin{array}{l}\text { Fue el novato por Coperfield } \\
\text { que el truco aprendió. }\end{array}$ & $\begin{array}{l}\text { Foi o menino de geografia } \\
\text { que o livro perdeu. }\end{array}$ \\
\hline & 36 & $\begin{array}{l}\text { It was the garbage collector } \\
\text { that the trash can emptied. }\end{array}$ & $\begin{array}{l}\text { Fue el cazador de fantasmas } \\
\text { que el engaño quizo hacer. }\end{array}$ & $\begin{array}{l}\text { Foi o catador de lixo que a } \\
\text { lixeira limpava. }\end{array}$ \\
\hline & 37 & $\begin{array}{l}\text { It was the child that the } \\
\text { multiplication tables learned. }\end{array}$ & $\begin{array}{l}\text { Fue la dama que las medias } \\
\text { de seda compró. }\end{array}$ & $\begin{array}{l}\text { Foi a criança que a tabuada } \\
\text { de multiplicação aprendeu. }\end{array}$ \\
\hline & 38 & $\begin{array}{l}\text { It was the President that the } \\
\text { crime bill vetoed. }\end{array}$ & $\begin{array}{l}\text { Fue el video que el } \\
\text { estudiante presentó. }\end{array}$ & $\begin{array}{l}\text { Foi o homem que a pizza } \\
\text { comeu. }\end{array}$ \\
\hline
\end{tabular}

Fonte: Elaborado pelos autores. 
Além disso, utilizamos expressões conhecidas do público brasileiro para aumentar sua familiaridade com as frases. Por exemplo, na frase 32, It was the soap opera that the housekeeper watched (Foi a novela das oito que a dona de casa assistiu), traduzimos "soap opera" para "novela das oito", que é uma expressão um pouco mais específica que a original, mas que é amplamente conhecida. Por outro lado, na frase 38, It was the President that the crime bill vetoed, tivemos dificuldade em traduzir "crime bill" para uma expressão que fosse natural para o público brasileiro. Logo, optamos por modificar o sentido completo da frase e a traduzimos para Foi o homem que a pizza comeu.

Os exemplos apresentados acima ilustram critérios fonológicos e semânticos que seguimos em nosso estudo, em especial nas frases clivadas de objeto. No Quadro 3, outros são apresentados, em especial com relação às palavras finais.

Quadro 3 - Processo de tradução das frases relativas de sujeito.

\begin{tabular}{|c|c|c|c|c|}
\hline & № & Original & Espanhol & Tradução \\
\hline \multirow{11}{*}{ 莺 } & 39 & $\begin{array}{l}\text { The car in which the } \\
\text { president rode was designed } \\
\text { for an actress. }\end{array}$ & $\begin{array}{l}\text { El baúl en el que el juguete } \\
\text { se guardó fue comprado por } \\
\text { un vago. }\end{array}$ & $\begin{array}{l}\text { O carro em que o presidente } \\
\text { andou foi feito para uma } \\
\text { atriz. }\end{array}$ \\
\hline & 40 & $\begin{array}{l}\text { The long test given at school } \\
\text { was assumed to measure } \\
\text { intelligence. }\end{array}$ & $\begin{array}{l}\text { Los payasos invitados a la } \\
\text { fiesta fueron contratados } \\
\text { para alegrar la tarde. }\end{array}$ & $\begin{array}{l}\text { O longo teste que foi } \\
\text { dado no curso media a } \\
\text { inteligência das pessoas. }\end{array}$ \\
\hline & 41 & $\begin{array}{l}\text { The evaluation that thestudent } \\
\text { wrote pleased the professor. }\end{array}$ & $\begin{array}{l}\text { El doctor curo a la viejita que } \\
\text { estaba enferma. }\end{array}$ & $\begin{array}{l}\text { A redação que o aluno } \\
\text { escreveu agradou a banca. }\end{array}$ \\
\hline & 42 & $\begin{array}{l}\text { The instruction that the boss } \\
\text { gave confused the secretary. }\end{array}$ & $\begin{array}{l}\text { El calculo que el cientifico } \\
\text { explico impacto a la audiencia. }\end{array}$ & $\begin{array}{l}\text { As instruções que o supervi- } \\
\text { sor deu confundiram o fiscal. }\end{array}$ \\
\hline & 43 & $\begin{array}{l}\text { The package that the driver } \\
\text { delivered thrilled the recipient. }\end{array}$ & $\begin{array}{l}\text { El video que el estudiante } \\
\text { presento le gusto al maestro. }\end{array}$ & $\begin{array}{l}\text { O pacote que o motorista } \\
\text { deixou animou o rapaz. }\end{array}$ \\
\hline & 44 & $\begin{array}{l}\text { The lawyer with the good } \\
\text { reputation was hired by the } \\
\text { criminals. }\end{array}$ & $\begin{array}{l}\text { El malandro con el tatuaje } \\
\text { fue contratado por el mafioso. }\end{array}$ & $\begin{array}{l}\text { O advogado que tinha boa } \\
\text { reputação foi contratado } \\
\text { pela máfia. }\end{array}$ \\
\hline & 45 & $\begin{array}{l}\text { The woman who knew Sam } \\
\text { well thought he was a good } \\
\text { cook. }\end{array}$ & $\begin{array}{l}\text { El maestro que enseña a } \\
\text { Juan piensa que es muy buen } \\
\text { estudiante. }\end{array}$ & $\begin{array}{l}\text { A mulher que comprou } \\
\text { a casa fez uma grande } \\
\text { reforma. }\end{array}$ \\
\hline & 46 & $\begin{array}{l}\text { The food that Nathan } \\
\text { prepared poisoned Susan. }\end{array}$ & $\begin{array}{l}\text { El ratón que Pedro descubrió } \\
\text { asustó a Marisol. }\end{array}$ & $\begin{array}{l}\text { A comida que Paulo fez } \\
\text { envenenou a moça. }\end{array}$ \\
\hline & 47 & $\begin{array}{l}\text { The insects that the girl } \\
\text { collected disgusted her mother. }\end{array}$ & $\begin{array}{l}\text { El articulo que escribio el } \\
\text { periodista le gusto al publico. }\end{array}$ & $\begin{array}{l}\text { Os insetos que a menina cole- } \\
\text { cionava assustavam sua mãe. }\end{array}$ \\
\hline & 48 & $\begin{array}{l}\text { The house that Jack built } \\
\text { burned down. }\end{array}$ & $\begin{array}{l}\text { La jaula que Salvador compró } \\
\text { se calló. }\end{array}$ & $\begin{array}{l}\text { A casa que João construiu } \\
\text { pegou fogo. }\end{array}$ \\
\hline & 49 & $\begin{array}{l}\text { The plan that the politician } \\
\text { advocated interested the voter. }\end{array}$ & $\begin{array}{l}\text { La poesia que el escritor creo } \\
\text { le gusto a sus lectores. }\end{array}$ & $\begin{array}{l}\text { O plano que o político } \\
\text { adotou interessou ao eleitor }\end{array}$ \\
\hline
\end{tabular}

\begin{tabular}{|c|c|c|c|c|}
\hline & № & Original & Espanhol & Tradução \\
\hline \multirow{10}{*}{ 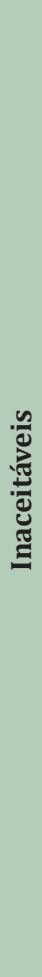 } & 50 & $\begin{array}{l}\text { The psychologist that the } \\
\text { advice gave puzzled the client. }\end{array}$ & $\begin{array}{l}\text { El chef que el pastel hizo le } \\
\text { gusto a los invitados. }\end{array}$ & $\begin{array}{l}\text { O psicólogo que foi dado pela } \\
\text { sugestão confundiu a jovem. }\end{array}$ \\
\hline & 51 & $\begin{array}{l}\text { The cook that the soup } \\
\text { prepared tasted good. }\end{array}$ & $\begin{array}{l}\text { La experta que la película } \\
\text { dirigió era pésima. }\end{array}$ & $\begin{array}{l}\text { O cozinheiro que a sopa fez } \\
\text { estava gostoso. }\end{array}$ \\
\hline & 52 & $\begin{array}{l}\text { The politician that the article } \\
\text { read angered him. }\end{array}$ & $\begin{array}{l}\text { El vagabundo que el perro } \\
\text { encontró lo acompañó. }\end{array}$ & $\begin{array}{l}\text { O político que a lei leu a } \\
\text { irritou. }\end{array}$ \\
\hline & 53 & $\begin{array}{l}\text { The plumber that the sink } \\
\text { installed fell apart. }\end{array}$ & $\begin{array}{l}\text { Elmecánico que la herramienta } \\
\text { hizo no funciona. }\end{array}$ & $\begin{array}{l}\text { O encanador que foi } \\
\text { instalado pela pia desabou. }\end{array}$ \\
\hline & 54 & $\begin{array}{l}\text { The students in the } \\
\text { conservative newspaper } \\
\text { infuriated the editorial. }\end{array}$ & $\begin{array}{l}\text { Fueron los músicos con cuerdas } \\
\text { delgadas los que molestaron } \\
\text { a los instrumentos. }\end{array}$ & $\begin{array}{l}\text { Foi o estoque que arrumou } \\
\text { os vendedores da loja de } \\
\text { sapatos. }\end{array}$ \\
\hline & 55 & $\begin{array}{l}\text { The cereal box that the prize } \\
\text { contained disappointed the } \\
\text { children. }\end{array}$ & $\begin{array}{l}\text { La canasta que el dulce } \\
\text { contenia le gusto a la niña. }\end{array}$ & $\begin{array}{l}\text { A caixa de cereal que vinha } \\
\text { no brinde decepcionou a } \\
\text { garota. }\end{array}$ \\
\hline & 56 & $\begin{array}{l}\text { The guests that the band } \\
\text { played entertained the music. }\end{array}$ & $\begin{array}{l}\text { Los niños que entretuvieron } \\
\text { en la fiesta le gustaron mucho } \\
\text { a los payasos. }\end{array}$ & $\begin{array}{l}\text { Os convidados que a banda } \\
\text { tocou distraiu a música. }\end{array}$ \\
\hline & 57 & $\begin{array}{l}\text { The restaurant who } \\
\text { performed in the opera that } \\
\text { Jenny saw was at the singer. }\end{array}$ & $\begin{array}{l}\text { La carretera quien trabajó en } \\
\text { la aduana que Ivan conoció } \\
\text { estaba en la vecina. }\end{array}$ & $\begin{array}{l}\text { O restaurante que se } \\
\text { apresentou na ópera que } \\
\text { Laura viu estava no cantor. }\end{array}$ \\
\hline & 58 & $\begin{array}{l}\text { The comedian that the joke } \\
\text { told amused the audience. }\end{array}$ & $\begin{array}{l}\text { La artista que la cancion } \\
\text { canto le gusto a la audiencia. }\end{array}$ & $\begin{array}{l}\text { O comediante que a piada } \\
\text { contou divertiu a plateia. }\end{array}$ \\
\hline & 59 & $\begin{array}{l}\text { The doctor that the diagnosis } \\
\text { gave upset the patient. }\end{array}$ & $\begin{array}{l}\text { El presidente que el discurso } \\
\text { dio no le gusto al publico. }\end{array}$ & $\begin{array}{l}\text { O médico que foi dado pelo } \\
\text { diagnóstico preocupou o } \\
\text { doente. }\end{array}$ \\
\hline
\end{tabular}

Fonte: Elaborado pelos autores. 
No Quadro 3, é possível perceber que modificamos completamente o sentidos das frases relativas de sujeito, números 45 e 54, respectivamente The woman who knew Sam well thought he was a good cook (A mulher que comprou a casa fez uma grande reforma) e The students in the conservative newspaper infuriated the editorial (Foi o estoque que arrumou os vendedores da loja de sapatos). Nesses casos, as opções de tradução que desenvolvemos aumentariam excessivamente o número de palavras nas frases ou não faziam muito sentido em um contexto brasileiro. Por essas razões, preferimos manter o comprimento das frases e a estrutura sintática similar aos das originais e modificar seu sentido.

Quadro 4 - Processo de tradução das frases relativas de objeto

\begin{tabular}{|c|c|c|c|c|c|c|c|c|c|}
\hline & № & Original & Espanhol & Tradução & & № & Original & Espanhol & Tradução \\
\hline \multirow{17}{*}{$\frac{n}{e^{\circ}}$} & 60 & $\begin{array}{l}\text { The parent hugged the child } \\
\text { that made the birthday card. }\end{array}$ & $\begin{array}{l}\text { La mujer engañó al hombre } \\
\text { que hizo trampa. }\end{array}$ & $\begin{array}{l}\text { O pai abraçou o filho que fez } \\
\text { o cartão de natal. }\end{array}$ & \multirow{17}{*}{ 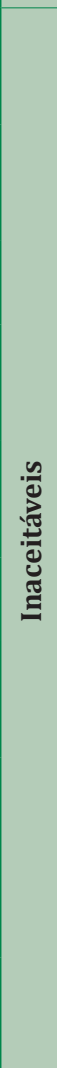 } & 70 & $\begin{array}{l}\text { The killer kidnapped the } \\
\text { murder that witnessed the }\end{array}$ & $\begin{array}{l}\text { El panadero recogió el } \\
\text { restaurante que desperdició }\end{array}$ & $\begin{array}{l}0 \text { assassino raptou a morte } \\
\text { que testemunhou o homem. }\end{array}$ \\
\hline & \multirow{2}{*}{61} & \multirow{2}{*}{$\begin{array}{l}\text { The man attacked the burglar } \\
\text { that sneaked into his house. }\end{array}$} & \multirow{2}{*}{$\begin{array}{l}\text { La abuela ayudó al gato que } \\
\text { entró por su jardín. }\end{array}$} & \multirow{2}{*}{$\begin{array}{l}\text { O homem atacou o bandido } \\
\text { que entrou em sua casa. }\end{array}$} & & & & & \multirow{3}{*}{$\begin{array}{l}\text { O discurso apresentou } \\
\text { a celebridade que deu o } \\
\text { repórter. }\end{array}$} \\
\hline & & & & & & \multirow{2}{*}{71} & \multirow{2}{*}{$\begin{array}{l}\text { The speech introduced the } \\
\text { celebrity that gave the host. }\end{array}$} & \multirow{2}{*}{$\begin{array}{l}\text { El libro presentó el escritor } \\
\text { que fue publicado. }\end{array}$} & \\
\hline & \multirow{2}{*}{62} & \multirow{2}{*}{$\begin{array}{l}\text { The angry woman slapped } \\
\text { the man that touched her leg. }\end{array}$} & \multirow{2}{*}{$\begin{array}{l}\text { El señor serio grito a la } \\
\text { señora que no lo escuchaba. }\end{array}$} & \multirow{2}{*}{$\begin{array}{l}\text { A mulher irritada bateu } \\
\text { no homem que tocou sua } \\
\text { perna. }\end{array}$} & & & & & \\
\hline & & & & & & \multirow[t]{2}{*}{72} & \multirow{2}{*}{$\begin{array}{l}\text { The dog bit the house that } \\
\text { robbed those intruders. }\end{array}$} & \multirow{2}{*}{$\begin{array}{l}\text { Los ladrones arrestaron al } \\
\text { policia que robo la tienda. }\end{array}$} & \multirow{2}{*}{$\begin{array}{l}\text { O cão mordeu a casa que } \\
\text { visitou as comadres. }\end{array}$} \\
\hline & \multirow[b]{2}{*}{63} & \multirow{2}{*}{$\begin{array}{l}\text { The tennis player hit the ball } \\
\text { that was out of bounds. }\end{array}$} & \multirow{2}{*}{$\begin{array}{l}\text { La señora recogio los } \\
\text { juguetes que estaban en el } \\
\text { suelo. }\end{array}$} & \multirow{2}{*}{$\begin{array}{l}\text { O jogador de futebol } \\
\text { chutou a bola que estava na } \\
\text { pequena área. }\end{array}$} & & & & & \\
\hline & & & & & & \multirow[t]{2}{*}{73} & \multirow{2}{*}{$\begin{array}{l}\text { The paper used the blue } \\
\text { pencil only to revise the } \\
\text { editor. }\end{array}$} & \multirow{2}{*}{$\begin{array}{l}\text { La secretaria llamo a las } \\
\text { facturas para revisar al } \\
\text { comprador. }\end{array}$} & \multirow{2}{*}{$\begin{array}{l}\text { O trabalho usou uma caneta } \\
\text { que era vermelha para } \\
\text { corrigir o professor. }\end{array}$} \\
\hline & \multirow[b]{2}{*}{64} & \multirow{2}{*}{$\begin{array}{l}\text { The murder mystery was so } \\
\text { engrossing that Maria forgot } \\
\text { about her meeting. }\end{array}$} & \multirow{2}{*}{$\begin{array}{l}\text { La película fue tan larga que } \\
\text { Rodrigo terminó en su cama. }\end{array}$} & \multirow[b]{2}{*}{$\begin{array}{l}\text { O filme estava tão bom que } \\
\text { Maria esqueceu sua reunião. }\end{array}$} & & & & & \\
\hline & & & & & & \multirow[t]{2}{*}{74} & \multirow{2}{*}{$\begin{array}{l}\text { The pool dove in to the } \\
\text { careless swimmer that was } \\
\text { empty. }\end{array}$} & \multirow{2}{*}{$\begin{array}{l}\text { El concierto canto en el } \\
\text { musico irreverente que } \\
\text { estaba lleno. }\end{array}$} & \multirow{2}{*}{$\begin{array}{l}\text { A piscina mergulhou no } \\
\text { nadador que estava vazio. }\end{array}$} \\
\hline & & The man loved the deep & La señora adora los nuevos & O homem podou as rosas & & & & & \\
\hline & 65 & $\begin{array}{l}\text { purple irises that were } \\
\text { growing in his yard. }\end{array}$ & $\begin{array}{l}\text { vestidos que compro en el } \\
\text { bazar. }\end{array}$ & $\begin{array}{l}\text { vermelhas que estavam } \\
\text { crescendo em seu jardim. }\end{array}$ & & 75 & $\begin{array}{l}\text { The car followed the man } \\
\text { that stole the detective. }\end{array}$ & $\begin{array}{l}\text { La estufa sirvió la sopa que } \\
\text { hirvió la cocinera. }\end{array}$ & $\begin{array}{l}\text { O carro seguiu o homem } \\
\text { que estacionou o espião. }\end{array}$ \\
\hline & 66 & $\begin{array}{l}\text { The woman met the author } \\
\text { that wrote the novel. }\end{array}$ & $\begin{array}{l}\text { El maestro corrijio el ensayo } \\
\text { del estudiante. }\end{array}$ & $\begin{array}{l}\text { A mulher conheceu o autor } \\
\text { que escreveu o romance. }\end{array}$ & & 76 & $\begin{array}{l}\text { The red barn jumped the } \\
\text { fence besides the horses. }\end{array}$ & $\begin{array}{l}\text { Los balones entrenaron a la } \\
\text { cancha con los jugadores. }\end{array}$ & $\begin{array}{l}\text { O celeiro vermelho pulou } \\
\text { a cerca que estava do lado }\end{array}$ \\
\hline & & The woman thanked the girl & La bestia atacó a la creatura & A mulher agradeceu à & & & & & \\
\hline & 67 & that found the wallet. & que descubrió el escondite. & $\begin{array}{l}\text { menina que achou sua } \\
\text { carteira. }\end{array}$ & & 77 & $\begin{array}{l}\text { The bowl ate the food that } \\
\text { was in the kitten. }\end{array}$ & $\begin{array}{l}\text { Los balones de futbol en la } \\
\text { cancha entrenaron con los }\end{array}$ & $\begin{array}{l}\text { O prato comeu a ração que } \\
\text { estava no cachorro. }\end{array}$ \\
\hline & & The scary dog bit the child & El reconocido actor saludó & 0 cão assustado mordeu a & & & & & \\
\hline & 68 & that pulled its tail. & $\begin{array}{l}\text { al hombre que compró su } \\
\text { mercancía. }\end{array}$ & $\begin{array}{l}\text { criança que pisou na sua } \\
\text { pata. }\end{array}$ & & 78 & $\begin{array}{l}\text { The spectators applauded the } \\
\text { goal that scored the player. }\end{array}$ & $\begin{array}{l}\text { Los sirvientes decoraron la } \\
\text { habitación que eligió el rey. }\end{array}$ & $\begin{array}{l}\text { A plateia aplaudiu os gols } \\
\text { que marcaram o jogador. }\end{array}$ \\
\hline & 69 & $\begin{array}{l}\text { The firefighter rescued the } \\
\text { boy that was trapped in the } \\
\text { apartment. }\end{array}$ & $\begin{array}{l}\text { La maestra calificó al alumno } \\
\text { que presentaba atento en el } \\
\text { simposio. }\end{array}$ & $\begin{array}{l}\text { O bombeiro salvou o gato } \\
\text { que estava preso na árvore. }\end{array}$ & & 79 & $\begin{array}{l}\text { The teacher rewarded the } \\
\text { question that answered the } \\
\text { student. }\end{array}$ & $\begin{array}{l}\text { El amigo repitió la canción } \\
\text { que cantaba el coro. }\end{array}$ & $\begin{array}{l}\text { O professor recompensou } \\
\text { a questão que acertou o } \\
\text { aluno. }\end{array}$ \\
\hline
\end{tabular}

Fonte: Elaborado pelos autores. 
Além disso, a frase 46, The food that Nathan prepared poisoned Susan, foi traduzida para A comida que Paulo fez envenenou a moça, pois nomes próprios como palavras finais poderiam se destacar dentre as outras palavras e, assim, facilitar sua memorização. Ainda, na frase 58, The comedian that the joke told amused the audience ( $O$ comediante que a piada contou divertiu a plateia), substituímos "audience" por "plateia", pois esta última é mais comumente utilizada em contexto de apresentação teatral no Brasil do que a primeira. E, na frase 59, The doctor that the diagnosis gave upset the patient (O médico que foi dado pelo diagnóstico preocupou o doente), optamos por utilizar "doente", pois "paciente" contém quatro sílabas, característica que procuramos evitar.

Novamente, seguimos critérios semânticos e também ortográficos para a seleção de palavras durante a tradução das frases relativas de sujeito. Outros exemplos ainda são apontados no Quadro 4, retro.

No Quadro 4, é possível perceber que realizamos pequenas mudanças de sentido em algumas frases relativas de objeto, como a 69 e a 73, The firefighter rescued the boy that was trapped in the apartment ( $O$ bombeiro salvou o gato que estava preso na árvore) e The paper used the blue pencil only to revise the editor ( $O$ trabalho usou uma caneta que era vermelha para corrigir o professor).

No caso do primeiro par de frases, optamos pelo contexto escolar de correção de trabalhos com caneta vermelha, pois é mais familiar para o público brasileiro do que o contexto de revisão de edição. No caso do segundo par de frases, trocamos a palavra final "apartamento" por "árvore" para evitar palavras com mais de três sílabas na tarefa de memorização, o que poderia dificultar sua realização.

Além disso, na frase 60,The parent hugged the child that made the birthday card (O pai abraçou o filho que fez o cartão de natal), substituímos "cartão de aniversário" por "cartão de natal" debido ao fato de "aniversário" conter cinco sílabas. E no caso da frase 72, The dog bit the house that robbed those intruders (O cão mordeu a casa que visitou as comadres), a palavra "intrusos" não é comumente utilizada em um contexto de assalto em português brasileiro. Por isso, preferimos modificar o sentido da frase.

Por fim, nos Quadros 1 a 4, é possível perceber que a versão em espanhol das frases não apresentou um padrão de manutenção do sentido das frases originais. Por isso, não utilizamos com frequência essa versão como auxílio, já que procuramos manter a versão traduzida para o português do teste o mais similar possível à original em inglês.

De modo geral, um dos nossos principais cuidados durante a tradução do teste de capacidade de MT de Waters e Caplan (1996a) foi tornar os significados das frases o mais naturais possível para o público brasileiro. Esse critério foi motivado pelo nosso estudo-piloto, durante o qual alguns participantes relataram ter dificuldade de julgar algumas frases que pareciam incomuns ou estranhas. Em segundo lugar, procuramos controlar o número de sílabas e a ocorrência das palavras finais, no sentido de evitar palavras com mais de três sílabas e a repetição da mesma palavra durante o teste. Um exemplo do último critério é a palavra "jardim", que apareceria duas vezes em posição final. Em uma dessas ocorrências, realizamos a troca dessa palavra por "flores". Em terceiro lugar, também tomamos cuidado para manter a estrutura sintática das frases originais. Essa tarefa foi mais simples de realizar do que, por exemplo, controlar o comprimento das frases, já que as estruturas sintáticas em questão também existem no português. Todos esses critérios serviram para controlarmos nossa tradução do reading span test de Waters e Caplan (1996a) a fim de mantê-la o mais similar possível do original, por se tratar de um teste já validado e confiável. 


\section{Discussão}

O objetivo deste estudo foi a tradução para o português e a adaptação do teste de Capacidade de Memória de Trabalho de Waters e Caplan (1996a) para o contexto brasileiro. Nossas motivações para tanto foram a diversa utilização desse reading span test com sucesso (WATERS e CAPLAN, 1996a; WALTER, 2007; YEH, 2011; CÁCERES, 2012) e também a necessidade de mais opções de testes de capacidade de MT em português, além da Bateria de Avaliação de Memória de Trabalho (WOOD et al., 2001).

Como citado anteriormente, a BAMT é composta de seis subtestes e pode ser aplicada por completo em 90 minutos, divididos em duas sessões (WOOD et al., 2001). Trata-se de uma bateria de testes longa e possivelmente exaustiva realizada em cadernos de papel padronizados. Essas características fazem com que seja de difícil aplicação. Há a possibilidade da taxa de evasão de participantes aumentar, comprometendo a validade interna do estudo. Além disso, é difícil prever, verificar e controlar eventos e mudanças individuais que podem ocorrer com os participantes no intervalo entre sessões. Seria preferível que todos os subtestes fossem realizados na mesma sessão, porém a performance dos participantes pode decair depois de 90 minutos de testes cognitivamente exigentes.

Outra questão importante é o fato de que a BAMT mede a capacidade de MT dos participantes offline, isto é, após a realização dos testes, não durante. Não é possível, por exemplo, registrar o tempo de reação aos estímulos. A aplicação da bateria em computador pode trazer praticidade e preencher uma lacuna na medição do construto. Contudo, a medição offline também dá conta do registro da acurácia da resposta e da verificação da compreensão, por exemplo. Ainda, ao contrário de uma medição online, a offline oferece um ambiente mais natural para o participante, preservando mais a validade externa do estudo.

Por outro lado, a aplicação da nossa tradução do teste de capacidade de MT dura em torno de 30 minutos e pode variar dependendo da rapidez com que o participante responde ao teste. Além disso, pode ser realizada no computador e medir online o tempo de reação aos estímulos e tempo de resposta. Assim, o teste de capacidade de MT pode medir compreensão, retenção e velocidade de processamento.

Tanto a BAMT quando nossa tradução da reading span test possuem critérios claros de escolha linguística. Wood et al. (2001) também controlaram o número de palavras na frase e o comprimento dessas palavras, para o qual estipularam um limite de duas sílabas; selecionaram as palavras com frequência de uso mais alta para facilitar sua compreensão; evitaram estruturas complexas, como voz passiva e relativas de sujeito-objeto e objeto-objeto; e controlaram as classes de palavras e seu status semântico (concretude/abstração).

Enquanto Wood et al. (2001) escolheram palavras e frases para a construção dos subtestes, a nossa seleção de palavras se restringiu a duas situações. A primeira, na qual procuramos manter o sentido original da frase de modo que ainda soasse natural para o falante brasileiro, e a segunda, na qual mudamos o significado da frase para aproximá-la do nosso contexto. Assim, nossa escolha foi determinada pelas palavras originais em inglês ou pela frequência de uso das palavras em português.

Após a menção de diferenças entre as duas medidas de capacidade de MT, é possível afirmar que há espaço para a utilização tanto de uma quanto de outra em futuras pesquisas. Porém, ao contrário da BAMT, a reading span test traduzida ainda não foi validada. O processo de validação do teste de capacidade de MT está em seu início e fará parte dos nossos próximos estudos. 


\section{Conclusão}

Neste estudo, realizamos a tradução para o português e a adaptação para o contexto brasileiro do teste de capacidade de Memória de Trabalho de Waters e Caplan (1996a). Também comparamos seu funcionamento com o da Bateria de Avaliação de Memória de Trabalho (WOOD et al., 2001) e delineamos um espaço para cada uma dessas medidas em estudos futuros. Além disso, relembramos que o teste aqui trabalhado é complexo por demandar a realização de duas tarefas cognitivas simultaneamente, e que essa complexidade pode ser aumentada através da leitura em voz alta das frases, como demonstrado por Tomitch $(1995,1999-2000)$. Por fim, enfatizamos a necessidade da medida traduzida ser validada para poder ser utilizada com confiabilidade em outras pesquisas.

\section{Referências}

ARDILA, Alfredo. Language representation and working memory with bilinguals. Journal of Communication Disorders, v. 36, p. 233-240, 2003. https://doi.org/10.1016/S00219924(03)00022-4

AREAAS DA LUZ FONTES, Ana B.; SCHWARTZ, Ana I. Working memory influences on cross-language activation during bilingual lexical disambiguation. Bilingualism: Language and Cognition, v. 14, n. 3, p. 360-370, 2011. https://doi.org/10.1017/S1366 728910000374

AZEVEDO, Aline Fay de. Listening comprehension and working memory capacity in beginning L2 learners: an exploratory study. Dissertação (Mestrado em Letras) - Pontifícia Universidade Católica do Rio Grande do Sul. 2012.

BADDELEY, Alan. D. Short-term and working memory. In: TULVING, E.; CRAIK, F. I. M. (Org.). The Oxford Handbook of Memory. New York: Oxford University Press, 2000. p. 77-92.

BADDELEY, Alan. Working Memory. In: BADDELEY, A. D.; EYSENCK, M. W.; ANDERSON, M. Memory. Hove: Psychology Press, 2009, p. 41-68.
BAILER, Cyntia. Working Memory Capacity and Attention to Form and Meaning in EFL Reading. Dissertação (Mestrado em Letras) - Universidade Federal de Santa Catarina. 2011.

BELACCHI, Carmen; BENELLI, Beatrice; PANTALEONE, Silvia. The influence of categorical organization on verbal working memory. British Journal of Developmental Psychology, v. 29, p. 942-960, 2011. https://doi.org/10.1111/j.2044-835X.2011.02030.x

CÁCERES, Glenda Heller. O papel da experiência linguística na relação entre alcance de memória de trabalho e compreensão leitora. Dissertação (Mestrado) - Universidade Federal do Rio Grande do Sul. 2012. Disponível em: <http://hdl.handle.net/10183/ 56581> Acesso em: 11 out. 2015.

CARRIEDO, Nuria; ELOSÚA, Rosa; GARCÍA-MADRUGA, Juan A. Working Memory, Text Comprehension, and Propositional Reasoning: A New Semantic Anaphora WM Test. The Spanish Journal of Psychology, v. 14, n. 1, p. 37-49, 2011. https://doi.org/10.5209/ rev_SJOP.2011.v14.n1.3

CASPARI, Isabelle; PARKINSON, Stanley R.; LAPOINTE, Leonard L.; KATZ, Richard C. Working Memory and Aphasia. Brain and Cognition, v. 37, p. 205-223, 1998.

COWAN, Nelson. Evolving Conceptions of Memory Storage, Selective Attention, and Their Mutual Constraints Within the Human Information-Processing System. Psychological Bulletin, v. 104, n. 2, p. 163-191, 1988. https://doi.org/10.1037/0033-2909.104.2.163

COWAN, Nelson. The Magical Mystery Four: How Is Working Memory Capacity Limited, and Why? Current Directions in Psychological Sciences, v. 19, n. 1, p. 51-57, 2010. https:// doi.org/10.1177/0963721409359277

COWAN, Nelson. Multiple Concurrent Thoughts: The Meaning and Developmental Neuropsychology of Working Memory. Developmental Neuropsychology, v. 35, n. 5, p. 447-474, 2010. https://doi.org/10.1080/87565641.2010.494985

DANEMAN, Meredyth.; CARPENTER, Patricia. Individual Differences in Working Memory and Reading. Journal of verbal learning and verbal behavior, n. 19, p. 450-466, 1980.

DANEMAN, M; MERIKLE, P. M. Working memory and language comprehension: A meta-analysis. Psychonomic Bulletin \& Review, v. 3, n. 4, p. 422-433, 1996. https://doi. org/10.3758/BF03214546

ENGLE, Randall W. Role of working-memory capacity in cognitive control. Current Anthropology, v. 51, s. 1, p. S17-S26, 2010. 
ENGLE, Randall W. Working Memory Capacity as Executive Attention. Current Directions in Psychological Science. v. 11, n. 1, p. 19-23, Feb. 2002. https://doi.org/10.1111/14678721.00160

ENGLE, Randall W.; KANE, Michael J.; TUHOLSKI, Stephen W. Individual Differences in Working Memory Capacity and What They Tell Us About Controlled Attention, General Fluid Intelligence, and Functions of the Prefrontal Cortex. In: MIYAKE, Akira; SHAH, Priti. Models of Working Memory. Cambridge, UK: Cambridge University Press, p. 102-134, 1999. HASHIMOTO, Ryu-ichiro; LEE, KangUk; PREUS, Alexander; MCCARLEY, Robert W.; WIBLE, Cynthia G. An fMRI Study of Functional Abnormalities in the Verbal Working Memory System and the Relationship to Clinical Symptoms in Chronic Schizophrenia. Cerebral Cortex, v. 20, n. 1, p. 46-60, 2010. https://doi.org/10.1093/cercor/bhp079

HAVIK, Else; ROBERTS, Leah; HOUT, Roeland van; SCHREUDER, Robert; HAVERKORT, Marco. Processing Subject-Object Ambiguities in the L2. Language Learning, v. 59, n. 1, p. 73-112, 2009.

IVANOVA, Maria V.; HALLOWELL, Brooke. A new modified listening span task to enhance validity of working memory assessment for people with and without aphasia. Journal of Communication Disorders, v. 52, p. 78-98, 2014. https://doi.org/10.1016/j. jcomdis.2014.06.001

JUST, Marcel Adam; CARPENTER, Patricia A. A Capacity Theory of Comprehension: Individual Differences in Working Memory. Psychological Review, v. 99, n. 1, p. 122-149, 1992. https://doi.org/10.1037/0033-295X.99.1.122

LINCK, Jared A.; OSTHUS, Peter; KOETH, Joel T.; BUNTING, Michael F. Working memory and second language comprehension and production. Psychonomic Bulletin and Review, v. 21, p. 861-883, 2014. https://doi.org/10.3758/s13423-013-0565-2

MACIZO, Pedro; SORIANO, M. F.; PAREDES, N. Phonological and Visuospatial Working Memory in Autism Spectrum Disorders. Journal of Autism and Developmental Disorders, v. 46, n. 9, p. 2956-2967, 2016. https://doi.org/10.1007/s10803-016-2835-0

MILLMAN, R. E.; MATTYS, S. L. Auditory Verbal Working Memory as a Predictor of Speech Perception in Modulated Maskers in Listeners With Normal Hearing. Journal of Speech, Language, and Hearing Research, v. 60, n. 5, p. 1236-1245, 2017. https://doi. org/10.1044/2017_JSLHR-S-16-0105

MIYAKE, Akira; SHAH, Priti. Models of working memory: Mechanisms of active maintenance and executive control. New York: Cambridge University Press, 1999. https://doi.org/10.1017/CB09781139174909
MOBERLY, A. C.; HARRIS, M. S.; BOYCE, L.; NITTROUER, S. Speech Recognition in Adults With Cochlear Implants: The Effects of Working Memory, Phonological Sensitivity, and Aging. Journal of Speech, Language, and Hearing Research, v. 60, n. 4, p. 1046-1061, 2017. https://doi.org/10.1044/2016_JSLHR-H-16-0119

OSWALD, Frederick L.; MCABEE, Samuel T.; REDICK, Thomas S.; HAMBRICK, David Z. The development of a short domain-general measure of working memory capacity. Behavior Research Methods, v. 47, n. 4, p. 1343-1355, 2015. https://doi.org/10.3758/s13428014-0543-2

PREBIANCA, Gicele Vergine Vieira. EFL Speech Production: Exploring the relationship between working memory capacity and proficiency level. Signum: Estudos da Linguagem, v. 16, n. 2, p. 215-245, 2013. https://doi.org/10.5433/2237-4876.2013 v16n2p215

RICKER, Timothy J.; AUBUCHON, Angela M.; COWAN, Nelson. Working memory. Wiley Interdisciplinary Reviews: Cognitive Science, v. 1, n. 4, p. 573-585, jul./ago. 2010.

SÁEZ, Leilani Marie. The Influence of WM Functioning on the Reading and Language Performance. Dissertation (Doctor of Philosofy in Education). University of California, 2004.

SILVEIRA, Flávia de Sousa Dias da. Working Memory capacity and Lexical Access in Advanced Students of L2 English. Trabalho de Conclusão de Curso (Graduação em Letras). Universidade Federal do Rio Grande do Sul, 2011.

SÖRQVIST, Patrik; RÖNNBERG, Jerker. Episodic Long-Term Memory of Spoken Discourse Masked by Speech: What Is the Role for Working Memory Capacity? Journal of Speech, Language, and Hearing Research, v. 55, p. 210-218, 2012. https://doi.org/10.1044/10924388(2011/10-0353)

SWANSON, H. Lee; SACHSE-LEE, Carole. A Subgroup Analysis of Working Memory in Children with Reading Disabilities: Domain-General of Domain-Specific Deficiency? Journal of Learning Disabilities, v. 34, n. 3, p. 249-263, 2001. https://doi. org/10.1177/002221940103400305

TOMITCH, Lêda Maria Braga. Individual Differences in Working Memory Capacity and the Recall of Predicted Elements in the Text. LenguasModernas, v. 26-27, p. 31-51, 1999-2000.

TOMITCH, Lêda Maria Braga. Reading: Text Organization Perception and Working Memory Capacity. Tese (Doutorado em Letras) - Universidade Federal de Santa Catarina, 1995. 
VIEIRA, Paula Ribeiro. Investigação sobre fatores preditores do desempenho em decisão lexical em segunda língua. Dissertação (Mestrado em Letras) - Pontifícia Universidade Católica do Rio Grande do Sul. 2015.

WALTER, Catherine. First- to second-language reading comprehension: not transfer, but access. International Journal of Applied Linguistics, v. 17, n. 1, p. 14-37, 2007. https://doi. org/10.1111/j.1473-4192.2007.00131.x

WATERS, Gloria S.; CAPLAN, David. The Measurement of verbal working memory capacity and its relation to reading comprehension. The Quarterly Journal of Experimental Psychology, 49A, 51-75, 1996a.

WATERS, Gloria S.; CAPLAN, David; HILDEBRANDT, Nancy. Working memory and written sentence comprehension. Attention and Performance XII, p. 531-555, 1987.

WEISBERG, S. M.; NEWCOMBE, N. S. How Do (Some) People Make a Cognitive Map? Routes, Places, and Working Memory. Journal of Experimental Psychology, Learning, Memory, and Cognition, v. 42, n. 5, p. 768-785, 2016. https://doi.org/10.1037/xlm0000200

WOOD, Guilherme Maia de Oliveira; CARVALHO, Maria Raquel Santos; ROTHE-NEVES, Rui; HAASE, Vitor Geraldi. Validação da Bateria de Avaliação da Memória de Trabalho (BAMT-UFMG). Psicologia: Reflexão e Crítica, v. 14, n. 2, p. 325-341, 2001. https://doi. org/10.1590/S0102-79722001000200008

YEH, Li-Hao. The role of cross-language activation in syntactic ambiguity. Doutorado, University of Texas, El Paso. 2011. Disponível em: <http://digitalcommons.utep.edu/ dissertations/AAI3457763>. Acesso em: 11 set. 2016.

Recebido em 25/01/2017.

Aceito em 24/07/2017. 